\title{
Constitutive Modelling of Short-Term Tensile Response of Geotextile Subjected to Mechanical and Abrasion Damages
}

\author{
António Miguel Paula ${ }^{1,4}$ [D Margarida Pinho-Lopes ${ }^{2,3,4}$
}

Received: 16 July 2021 / Accepted: 25 August 2021

(c) The Author(s), under exclusive licence to Springer Nature Switzerland AG 2021

\begin{abstract}
This paper discusses simple constitutive models to represent the tensile response of a geotextile (GTX) and the influence of two endurance durability factors on that response: mechanical and abrasion damage, acting independently and sequentially. The damage was induced in laboratory under standard conditions. Two types of models were used: polynomial and hyperbolic. The polynomial models (order 4 and 6) approximated the short-term tensile experimental data very well (and better than the hyperbolic model), but its model parameters have no physical meaning. The hyperbolic model parameters did not always have the physical meaning reported in the literature. Correction factors were introduced successfully, to achieve that physical meaning. These correction factors were not materials constants and were affected by the damage induced, and by the type of aggregate used in the mechanical damage tests. Equations to estimate the model parameters of the damaged samples were proposed using the model parameters for the undamaged sample and its properties (tensile strength and corresponding correction factor), and the reduction factors allowing for damage for the initial stiffness $\left(J_{i}\right)$ and tensile strength $\left(T_{\max }\right)$.
\end{abstract}

Keywords Constitutive models $\cdot$ Geotextile $\cdot$ Mechanical damage $\cdot$ Abrasion damage $\cdot$ Tensile response $\cdot$ Physical meaning $\cdot$ Durability

\section{Introduction}

The tensile properties of geosynthetics are extremely important in geosynthetic design. Particularly for soil reinforcement applications, the relevant design parameters are usually the maximum tensile strength and strain. Numerical models are becoming more and more popular to assist the

António Miguel Paula

mpaula@ipb.pt

$\triangle$ Margarida Pinho-Lopes

mlopes@ua.pt

1 Department of Applied Mechanics, Polytechnic Institute of Bragança, 5300-253 Bragança, Portugal

2 RISCO, Department of Civil Engineering, University of Aveiro, Campus Universitário de Santiago, 3810-193 Aveiro, Portugal

3 Faculty of Engineering and Physical Sciences, University of Southampton, Boldrewood Innovation Campus, Southampton SO16 7QF, UK

4 CONSTRUCT-GEO, Department of Civil Engineering, Faculty of Engineering, University of Porto, Rua Dr. Roberto Frias, s/n, 4200-465 Porto, Portugal design of reinforced soil structures. Often, in such models, geosynthetics are represented by simple linear-elastic constitutive models, i.e., a stiffness (sometimes a maxi-mum tensile strength can be included). However, the response of geosynthetics to loading can be represented by non-linear constitutive models. The tensile properties of geosynthetics may be significantly impacted by mechanical and abrasion damages, which may reduce the available tensile strength, strain and stiffness.

Geosynthetics need to be designed to maintain adequate levels of their functional properties throughout their design life, i.e., to have adequate durability. The durability of geosynthetics is affected by endurance factors, related to the resistance of geosynthetics, and degradation factors, resulting from changes of the polymer at molecular level [1,2]. Examples of factors affecting the durability of geosynthetics include: mechanical damage, creep, stress relaxation, abrasion, high temperatures, oxidation, weathering factors (particularly ultraviolet, UV, radiation), and chemical factors. The relevance of the different factors depends on the project, the particular site conditions, and the construction processes and timings. 
Transportation and handling of the materials and their installation on site often lead to mechanical damage. The damage mechanisms and degree of mechanical damage depend on the geosynthetic (structure, constituent polymer and some physical and mechanical properties), the backfill material (particle size and angularity), the foundation soil (stiffness and strength), the installation method (procedures and equipment used, height of soil layers) and the weather conditions [3-6]. For some applications, mechanical stresses associated with installation are the highest stresses geosynthetics are submitted to during their design life [5]. The consequences of installation damage may include: superficial abrasion; localised thickness reductions; fibre cutting; puncturing; complete disintegration within a given area of geosynthetic, which likely will lead to reductions in tensile strength [7]. Although usually installation damage is associated with loss of resistance, a residual stiffness modulus measures the resistance to site installation damage more adequately for woven polyester geogrids and polyethylene geogrids $[6,8]$. The assessment of installation damage and its consequences to the functional properties of geosynthetics should be done using field tests, under conditions similar to the project, and following standardised procedures [9]. Examples of such procedures include: Annex D of BS 8600-1 [10], ASTM D5818 [11] and NorGeoSpec 2012 [12]. Nevertheless, many authors have used laboratory tests to simulate such damage [5, 6, 13-15]. Some authors carried out mechanical damage laboratory tests by adapting a standard procedure $[16,17]$ using a natural aggregate and/ or changing the intensity of the cyclic load applied $[5,15$, $18,19]$.

The effect of mechanical damage associated with installation of geosynthetics have been analysed considering mostly the changes to their mechanical properties on the short term $[5,15,20-23]$ and on the long term [23-31]: Other studies included an assessment of the effect of mechanical damage on the hydraulic properties [20] and on the soil-geosynthetic interaction properties [23, 32-34].

Mechanical damage associated with installation is common to all applications of geosynthetics, as they are transported, handled, and placed on site. Additionally, for particular applications of geosynthetics, abrasion damage is also key (e.g., railways, temporary roads, canal revetments, seashores with sediments and sliding masses washing up and down). Abrasion damage is time dependent as it occurs mostly during service, particularly when cyclic relative motion (friction) between a geosynthetic and contact soil occurs. The abrasion damage leads to reduction of tensile strength and is related to the mass per unit area of the geosynthetic and, for railway applications, to the volume of traffic [35]. In hydraulic applications, abrasion can also be caused by turbid flow [36]. The existing standardised procedure to induce abrasion damage in laboratory
[37] can be linked to in-field abrasion using equations proposed by ISO [38].

The design of geosynthetics is often carried out using reduction factors, each representing a single factor or mechanism affecting the durability of geosynthetics, that are multiplied $[1,39,40]$. Nevertheless, positive or negative synergy between factors can occur, as reported by Rosete et al. [20] and Pinho-Lopes et al. [23]. Rosete et al. [20] studied the influence of mechanical and abrasion damage acting isolated and combined on the short-term tensile response and hydraulic properties of geosynthetics. These authors concluded that there can be interaction, positive or negative synergy between mechanical and abrasion damage, represented by a combined reduction factor different than the product between the corresponding independent reduction factors.

Numerical models, particularly using the finite element method, are becoming more and more popular for example to assist the design of structures with geosynthetics and/or analyse their performance. Often, in such models geosynthetics are represented by a stiffness and a tensile strength. As durability is key for the design and performance of geosynthetics, representing their response using non-linear constitutive models allowing for durability is essential. Thus, it is important to understand how damage may influence the load-strain response of geosynthetics and how such changes can influence the parameters used in design. Paula and Pinho-Lopes [41, 42] have used simple constitutive models allowing for durability aspects and presented initial work on this topic.

This paper focuses on two factors affecting the durability of geosynthetics: mechanical damage, often associated with installation, and abrasion damage, acting independently and sequentially. The influence of the type of aggregate used to induce mechanical damage is also analysed. The short-term tensile response of a geotextile submitted to mechanical damage and abrasion damage is represented using constitutive models. The model parameters are analysed and their ability to represent the damage induced is discussed. Equations to estimate the model parameters of the damaged samples are proposed using the model parameters for the undamaged sample and its properties, and the reduction factors for the damaged sample.

\section{Base Experimental Data}

Table 1 describes the different types of samples analysed to derive constitutive models and their parameters to represent the short-term tensile response of the geotextile (GTX) studied. 
Table 1 Test program implemented for the base experimental data and number of specimens tested

\begin{tabular}{llllllll}
\hline & UND & MEC & & & ABR & MEC SYN + ABR \\
\cline { 3 - 6 } & & SYN & GRA & LIM & & \\
\hline GTX & 5 & 5 & 5 & 5 & 5 & 5 \\
\hline
\end{tabular}

$U N D$ undamaged, $M E C$ mechanical damage, SYN synthetic aggregate, GRA granite aggregate, LIM limestone aggregate, $A B R$ abrasion damage, $M E C S Y N+A B R$ mechanical damage followed by abrasion damage

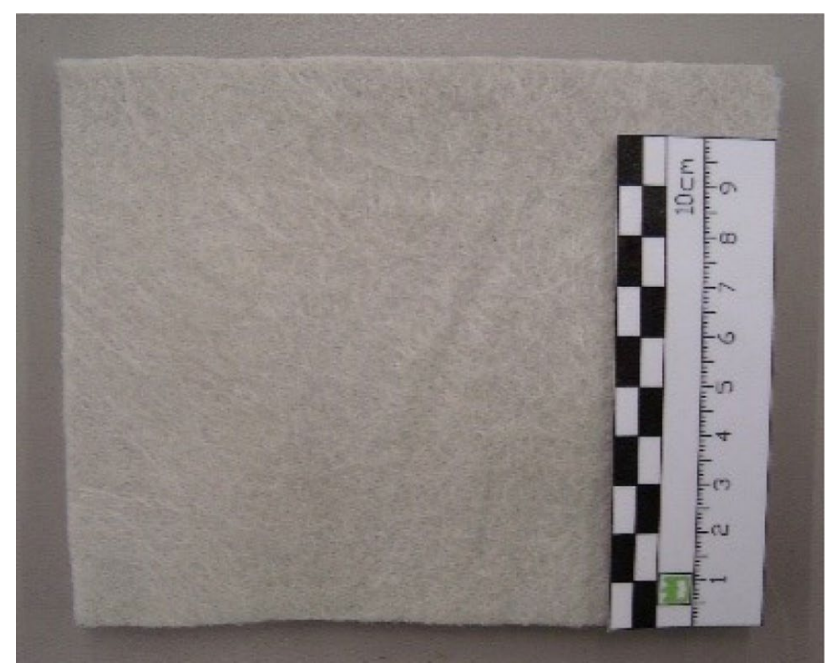

Fig. 1 Geotextile studied

\section{Geosynthetic}

GTX is a nonwoven geotextile formed by continuous polypropylene (PP) filaments mechanically bonded (Fig. 1). GTX has the following nominal properties: tensile strength $T_{\text {nom }}=50 \mathrm{kN} / \mathrm{m}$; strain for the tensile strength $\varepsilon_{\text {nom }}=65 \%$; mass per unit area $\mu_{\text {nom }}=800 \mathrm{~g} / \mathrm{m}^{2}$; thickness $d_{\text {nom }}=6 \mathrm{~mm}$. The tensile response of GTX was characterized using wide-width tensile tests, EN ISO 10319 [43], for different types of samples: reference material (undamaged) and after damage. GTX was submitted to index tests (Fig. 2) for inducing: (i) mechanical damage; (ii) abrasion damage; (iii) mechanical damage followed by abrasion damage.

\section{Laboratory Mechanical Damage Test}

A standardised procedure [16] was used to induce mechanical damage on GTX. During the test, a specimen of geosynthetic is placed between two layers of a synthetic aggregate (sintered aluminium oxide, particle sizes between 5 and $10 \mathrm{~mm}$ ) and submitted to cyclic loading.

The mechanical damage test is carried out using a container formed by two half boxes (Fig. 2a). Their dimensions are: $0.30 \times 0.30 \mathrm{~m}^{2}$ in plan section and $0.075 \mathrm{~m}$ high, each; the total height of the container is $0.15 \mathrm{~m}$. The load is applied using a rigid load plate with plan area of $0.10 \times 0.20$ $\mathrm{m}^{2}$.

During the assembly of the test, two layers of aggregate are placed and compacted in the lower half-box, up to a total height of $0.075 \mathrm{~m}$. For the compaction, a static pressure of $200 \mathrm{kPa}$ is applied during 1 min using a compaction plate with $0.30 \times 0.30 \mathrm{~m}^{2}$ in plan section. Then, a specimen of geosynthetic is placed on top of the lower half-box. The upper half-box is assembled and filled with loose aggregate $(0.075 \mathrm{~m}$ high$)$. The loading plate is positioned, centred and
Fig. 2 Overview of the test equipment: a mechanical damage tests; $\mathbf{b}$ abrasion damage tests
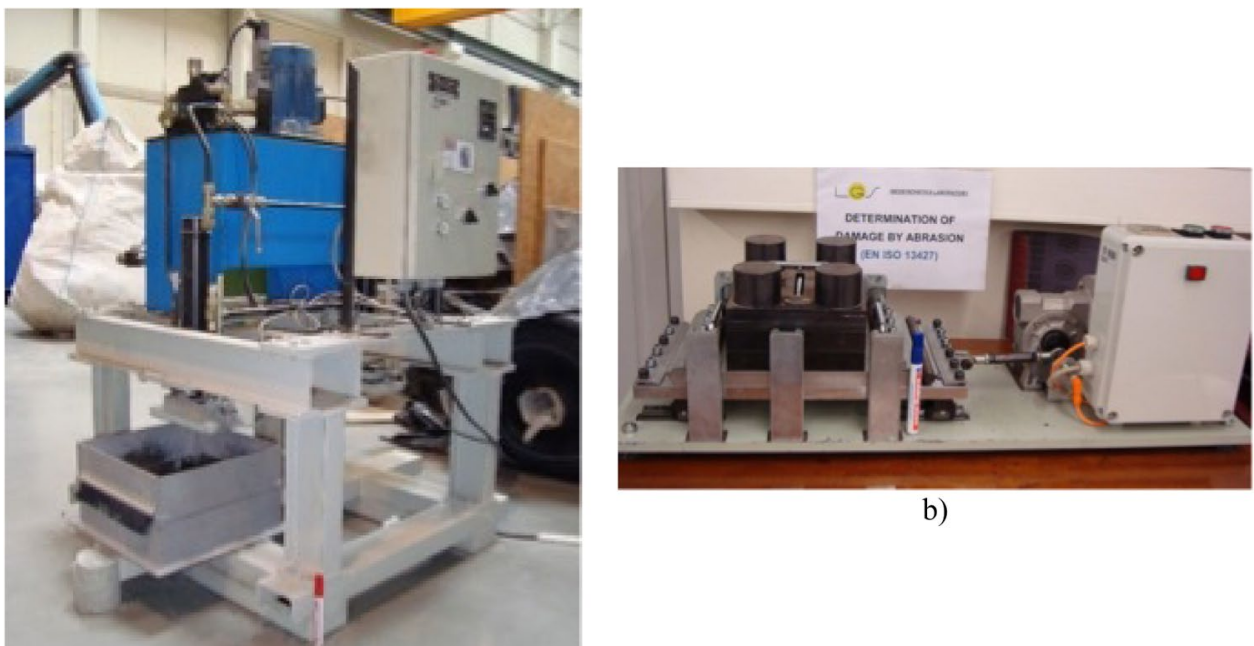

b) 
on top of the loose aggregate (Fig. 2a). The test ends after a cyclic loading ranging between 5 and $900 \mathrm{kPa}$, with frequency of $1 \mathrm{~Hz}$ for 200 cycles, is applied.

The dimensions of the specimens submitted to mechanical damage $(0.20 \mathrm{~m}$ wide and $1.0 \mathrm{~m}$ long) are adequate to perform wide-width tensile tests for characterising the mechanical damage induced. The area of the load plate coincides with the area of geosynthetic to be placed between clamps for a tensile test. A minimum of five specimens were tested.

The test method used [16] and later (updated) versions (such as [44]) define ways of ensuring that the aggregate maintains its characteristics during the tests. Thus, if necessary, after every three uses the aggregate should be wet sieved (using a 5-mm aperture sieve), and particles smaller than $5 \mathrm{~mm}$ should be discarded. All aggregate must be completely discarded after 20 uses.

Besides the tests performed with the synthetic aggregate prescribed in the test standard, two additional aggregates were used. These were natural aggregates, with minimum particle size analogue to that of the synthetic aggregate, and

Table 2 Properties of the aggregates used in the mechanical damage tests: minimum and maximum particle size and Los Angeles (LA) coefficient

\begin{tabular}{lllll}
\hline Aggregate & Type & $\begin{array}{l}D_{\min } \\
(\mathrm{mm})\end{array}$ & $\begin{array}{l}D_{\max } \\
(\mathrm{mm})\end{array}$ & $\begin{array}{l}\text { LA coefficient } \\
(-)\end{array}$ \\
\hline SYN & $\begin{array}{c}\text { Sintered alu- } \\
\text { minium oxide }\end{array}$ & 5 & 10 & 16 \\
& Granite & 4.75 & 12.5 & 28 \\
GRA & Limestone & 4.76 & 19 & 19 \\
LIM &
\end{tabular}

$D_{\min }$ minimum particle sizes, $D_{\max }$ maximum particle sizes, $L A$ coefficient-Los Angeles abrasion coefficient with different petrography: granite; limestone (Table 2). Thus, three sets of mechanical damage tests were carried out following the procedures described and with the synthetic aggregate (SYN), the granite aggregate (GRA), and the limestone aggregate (LIM).

\section{Laboratory Abrasion Test}

The abrasion damage was simulated using the procedures in [45]. In this test, a geosynthetic specimen is placed on an upper plate of a stationary platform and rubbed by a P100 abrasive, placed on the lower plate and moved along a horizontal axis under controlled pressure (Fig. 2b). Some adjustments were made to the test procedure [20]: a P24 abrasive film was placed between the specimen and the upper plate, to ensure that during the test the specimen did not adhere to the abrasive film placed on the lower plate (no additional damage was observed).

\section{Short-Term Tensile Response}

The short-term tensile response of the geosynthetics was characterised following the procedures described in [45]. For each type of sample studied, five valid specimens were tested.

The tensile tests results are summarised in Table 3: tensile strength, $T_{\max }$ (herein defined as the maximum tensile force mobilised during the test); strain for maximum load, $\varepsilon_{\max }$; secant stiffness for $2 \%$ and $5 \%$ strain, $J_{\mathrm{s} 2 \%}$ and $J_{\mathrm{s} 5 \%}$, respectively. The results refer to five valid specimens per sample and include the corresponding coefficient of variation (CV). The secant stiffness for $x \%$ strain, $J_{\mathrm{sx} \%}$, was determined using Eq. 1, where $T_{x \%}$ is the force for $x \%$ strain measured during the tests.
Table 3 Summary of tensile tests results for different of samples of GTX

\begin{tabular}{|c|c|c|c|c|c|c|}
\hline \multicolumn{3}{|l|}{ GTX } & \multirow{2}{*}{$\begin{array}{l}T_{\max }(\mathrm{kN} / \mathrm{m}) \\
50.09\end{array}$} & \multirow{2}{*}{$\frac{\varepsilon_{\max }(\%)}{111.71}$} & \multirow{2}{*}{$\frac{J_{\mathrm{s} 2 \%}(\mathrm{kN} / \mathrm{m})}{107.54}$} & \multirow{2}{*}{$\frac{J_{\mathrm{s} 5 \%}(\mathrm{kN} / \mathrm{m})}{118.55}$} \\
\hline UND & & Average & & & & \\
\hline & & CV $(\%)$ & 5.32 & 1.64 & 14.94 & 5.65 \\
\hline & SYN & Average & 33.69 & 80.87 & 73.94 & 72.12 \\
\hline & & $\mathrm{CV}(\%)$ & 9.85 & 5.24 & 14.67 & 13.13 \\
\hline \multirow[t]{4}{*}{ MEC } & GRA & Average & 38.83 & 108.79 & 65.25 & 60.32 \\
\hline & & $\mathrm{CV}(\%)$ & 9.39 & 6.47 & 16.39 & 12.58 \\
\hline & LIM & Average & 44.13 & 111.56 & 70.66 & 67.25 \\
\hline & & $\mathrm{CV}(\%)$ & 3.03 & 6.29 & 14.16 & 11.50 \\
\hline \multirow{2}{*}{\multicolumn{2}{|c|}{ ABR }} & Average & 40.80 & 121.57 & 75.24 & 69.68 \\
\hline & & $\mathrm{CV}(\%)$ & 13.07 & 5.52 & 10.66 & 8.72 \\
\hline \multirow{2}{*}{\multicolumn{2}{|c|}{ MEC SYN + ABR }} & Average & 30.42 & 89.70 & 69.45 & 61.31 \\
\hline & & $\mathrm{CV}(\%)$ & 4.76 & 5.92 & 5.38 & 6.20 \\
\hline
\end{tabular}

$U N D$ undamaged, $M E C$ damage in laboratory, SYN synthetic aggregate, GRA granite aggregate, LIM limestone aggregate, $A B R$ abrasion, MEC SYN + ABR sequential mechanical and abrasion damage, $T_{\max }$ tensile strength, $\varepsilon_{\max }$ strain for maximum load, $\mathrm{J}_{\mathrm{s} 2 \%}$ secant stiffness for $2 \%$ strain, $\mathrm{J}_{\mathrm{s} 5 \%}$ secant stiffness for $5 \%$ strain, $C V$ coefficient of variation 
$J_{\mathrm{sx} \%}=\frac{T_{x \%} \times 100}{x}$.

The tensile strength of GTX was reduced after damage, with retained tensile strength ranging between 61 and $88 \%$. Samples of GTX submitted sequentially to mechanical damage (with the synthetic aggregate) and abrasion damage (MEC SYN + ABR) exhibited the largest reduction in tensile strength. The secant stiffness of GTX was also reduced by damage, with retained values ranging between 61 and $70 \%$ for $2 \%$ strain and between 51 and $61 \%$ for $5 \%$ strain.

The tensile response after mechanical damage was affected by the aggregate used in damage tests. The reductions in tensile strength were higher with the synthetic aggregate (33\%) than with the natural aggregates (granite, $22 \%$ and limestone, $12 \%$ ). The natural aggregates, with particles larger than those of the synthetic aggregate, were less aggressive to GTX. Particles of these aggregates responded differently to loading: the synthetic aggregate particles fragmented into smaller elements with sharp and angular edges and faces, more likely to induce damage; the natural aggregates, and in particular the granite aggregate, exhibited less fragmentation.

Figure 3 illustrates the load-strain responses obtained from the wide-width tensile tests for representative specimens of each sample. The reductions of tensile strength and corresponding strain and the reductions of stiffness are evident.

Simple constitutive modes, such as polynomial models and hyperbolic-based models, are be used to represent the short-time tensile response of geosynthetics. Curve fitting experimental data, namely using the least-squares method, allows defining the model parameters [46]. Equation 2

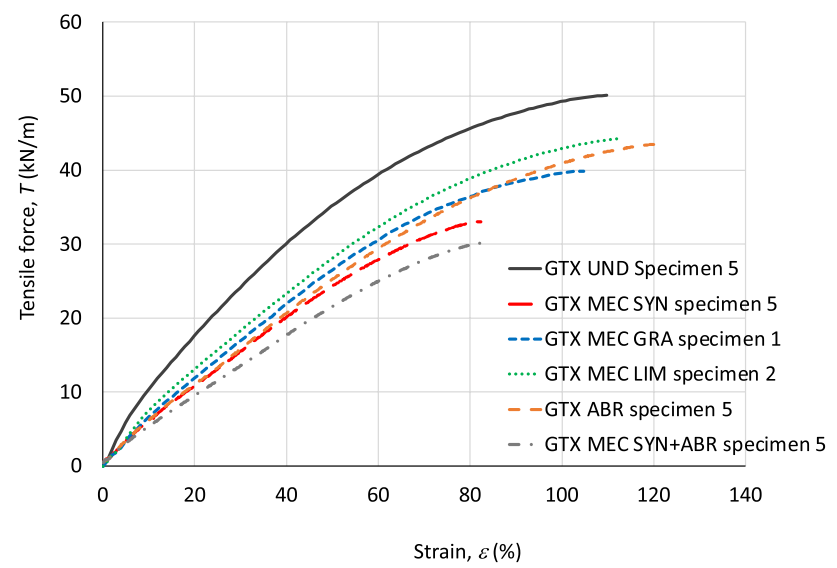

Fig. 3 Load-strain response for different types of samples of GTX (representative specimens): undamaged (UND) and submitted to damage in laboratory: mechanical (MEC); with synthetic (SYN), granite (GRA) and limestone (LIM) aggregates; abrasion (ABR); and sequential mechanical and abrasion damage (MEC SYN + ABR) represents a generic polynomial model, where $T$ is the load per unit width, $\varepsilon$ is the axial tensile strain, $a_{i}$ is the polynomial coefficient of order $i$ and $n$ is the order of the polynomial. Equation 3 represents the tangent stiffness $\left(J_{t \varepsilon \%}\right)$ of the geosynthetic for a strain $\varepsilon$ (in \%), obtained by derivation of Eq. 2. Equation 4 represents a hyperbolic model. According to Liu and Ling [47], $a$ and $b$ are model parameters representing the inverse of the initial stiffness, $J_{i}$, and the inverse of the tensile strength of the geosynthetic, $T_{\max }$ (Eqs. 6 and 7 , respectively).

$T=\sum_{i=0}^{n} a_{i} \varepsilon^{i}$

$J_{t \varepsilon \%}=\frac{d T}{d \varepsilon}=\sum_{i=1}^{n} a_{i} \varepsilon^{i-1}$.

$T=\frac{\varepsilon}{a+b \varepsilon}$

$J_{t \varepsilon \%}=\frac{d T}{d \varepsilon}=\frac{a}{(a+b \varepsilon)^{2}}$.

$a=\frac{1}{J_{i}}$

$b=\frac{1}{T_{\max }}$.

\section{Results and Discussion}

The experimental data were fitted with three simple constitutive models: two polynomials, order 4 and order 6 , and a hyperbolic model. The model parameters were obtained via curve fitting of the experimental data for each specimen; then, average model parameters were calculated.

Table 4 summarises the average model parameters for different samples of GTX: undamaged (UND) and submitted to laboratory damage: mechanical (MEC), with three different aggregates (SYN, GRA, LIM); abrasion (ABR); and mechanical damage (with the synthetic aggregate) followed by abrasion damage (MEC SYN + ABR). Table 4 includes values for the coefficient of determination $\left(R^{2}\right)$ of some of model parameters. Figure 4 includes load-strain curves for selected specimens of each sample obtained experimentally and with the constitutive models analysed.

The polynomial models fit the experimental data very well (Table 4; Fig. 4), with coefficient of determination, $R^{2}$, of 1.0 and coefficient of variation lower than $0.005 \%$. The 
Table 4 Model parameters for different types of samples of GTX

\begin{tabular}{|c|c|c|c|c|c|c|}
\hline \multirow{2}{*}{$\begin{array}{l}\text { Constitutive } \\
\text { model and } \\
\text { parameters }\end{array}$} & \multirow[t]{2}{*}{ UND } & \multicolumn{3}{|l|}{ MEC } & \multirow[t]{2}{*}{$\mathrm{ABR}$} & \multirow[t]{2}{*}{ MEC SYN + ABR } \\
\hline & & SYN & GRA & LIM & & \\
\hline \multicolumn{7}{|c|}{ Polynomial: 4} \\
\hline$a_{0}$ & 7.91E-01 & $5.75 \mathrm{E}-01$ & $3.26 \mathrm{E}-01$ & $2.48 \mathrm{E}-01$ & $9.41 \mathrm{E}-01$ & $7.08 \mathrm{E}-01$ \\
\hline$a_{1}$ & 9.94E-01 & $6.09 \mathrm{E}-01$ & $5.70 \mathrm{E}-01$ & $6.79 \mathrm{E}-01$ & 4.93E-01 & $4.57 \mathrm{E}-01$ \\
\hline$a_{2}$ & $-7.85 \mathrm{E}-03$ & $-4.37 \mathrm{E}-03$ & $-1.57 \mathrm{E}-03$ & $-2.87 \mathrm{E}-03$ & $3.55 \mathrm{E}-05$ & $-1.22 \mathrm{E}-03$ \\
\hline$a_{3}$ & $4.08 \mathrm{E}-05$ & $6.66 \mathrm{E}-05$ & $3.26 \mathrm{E}-06$ & $1.22 \mathrm{E}-05$ & $-1.45 \mathrm{E}-05$ & $1.62 \mathrm{E}-05$ \\
\hline$a_{4}$ & $-1.34 \mathrm{E}-07$ & $-5.35 \mathrm{E}-07$ & $-6.67 \mathrm{E}-08$ & $-8.62 \mathrm{E}-08$ & 2.34E-08 & $-2.04 \mathrm{E}-07$ \\
\hline$R^{2}$ & 1.000 & 1.000 & 1.000 & 1.000 & 1.000 & 1.000 \\
\hline $\mathrm{CV}\left(R^{2}\right)$ & 0.005 & 0.000 & 0.000 & 0.004 & 0.005 & 0.004 \\
\hline \multicolumn{7}{|c|}{ Polynomial: 6} \\
\hline$a_{0}$ & $3.56 \mathrm{E}-02$ & $1.39 \mathrm{E}-01$ & $-2.19 \mathrm{E}-01$ & $-3.61 \mathrm{E}-01$ & 3.99E-01 & 2.92E-01 \\
\hline$a_{1}$ & $1.26 \mathrm{E}+00$ & 8.01E-01 & 7.57E-01 & 8.83E-01 & $6.61 \mathrm{E}-01$ & $6.23 \mathrm{E}-01$ \\
\hline$a_{2}$ & $-2.96 \mathrm{E}-02$ & $-2.47 \mathrm{E}-02$ & $-1.64 \mathrm{E}-02$ & $-1.86 \mathrm{E}-02$ & $-1.24 \mathrm{E}-02$ & $-1.72 \mathrm{E}-02$ \\
\hline$a_{3}$ & 7.47E-04 & 9.37E-04 & 4.75E-04 & 4.97E-04 & $3.60 \mathrm{E}-04$ & $6.41 \mathrm{E}-04$ \\
\hline$a_{4}$ & $-1.10 \mathrm{E}-05$ & $-1.82 \mathrm{E}-05$ & $-7.17 \mathrm{E}-06$ & $-7.11 \mathrm{E}-06$ & $-5.33 \mathrm{E}-06$ & $-1.17 \mathrm{E}-05$ \\
\hline$a_{5}$ & 7.87E-08 & $1.69 \mathrm{E}-07$ & $5.08 \mathrm{E}-08$ & 4.80E-08 & 3.64E-08 & $1.01 \mathrm{E}-07$ \\
\hline$a_{6}$ & $-2.18 \mathrm{E}-10$ & $-6.21 \mathrm{E}-10$ & $-1.39 \mathrm{E}-10$ & $-1.24 \mathrm{E}-10$ & $-9.44 \mathrm{E}-11$ & $-3.38 \mathrm{E}-10$ \\
\hline$R^{2}$ & 1.000 & 1.000 & 1.000 & 1.000 & 1.000 & 1.000 \\
\hline $\mathrm{CV}\left(R^{2}\right)$ & 0.004 & 0.005 & 0.004 & 0.005 & 0.000 & 0.000 \\
\hline \multicolumn{7}{|l|}{ Hyperbolic } \\
\hline$a$ & 0.853 & 1.526 & 1.495 & 1.289 & 1.548 & 1.821 \\
\hline $\mathrm{CV}(a)$ & 9.327 & 9.969 & 12.624 & 8.128 & 10.901 & 6.415 \\
\hline$b$ & 0.012 & 0.011 & 0.011 & 0.010 & 0.011 & 0.011 \\
\hline $\mathrm{CV}(b)$ & 3.795 & 3.313 & 7.143 & 4.356 & 17.359 & 11.833 \\
\hline$R^{2}$ & 0.998 & 0.999 & 0.997 & 0.997 & 0.997 & 0.998 \\
\hline $\mathrm{CV}\left(R^{2}\right)$ & 0.070 & 0.013 & 0.077 & 0.069 & 0.050 & 0.085 \\
\hline
\end{tabular}

$U N D$ undamaged, $M E C$ damage in laboratory, $S Y N$ synthetic aggregate, GRA granite aggregate, LIM limestone aggregate, $A B R$ abrasion, $M E C S Y N+A B R$ sequential mechanical and abrasion damage, $C V$ coefficient of variation order 4 and order 6 polynomials provide a good approximation of the experimental data. The polynomial coefficients of order 0-4 are different for the two polynomial models studied; however, the order 6 polynomial model had very small coefficients of order 5 and order $6\left(\mathrm{a}_{5}: 1.69 \times 10^{-7}\right.$ to $3.64 \times 10^{-8} ; \mathrm{a}_{6}:-9.44 \times 10^{-11}$ to $\left.-6.21 \times 10^{-10}\right)$. Thus, order 4 polynomials were considered adequate approximations of the tensile response of GTX before and after damage. Nevertheless, for the GTX and the type of samples analysed, the short-term tensile response is defined mostly by the coefficients of order 0-2. It must be noted that the polynomial models are of little practical use as they are simple mathematical functions fitted to the experimental data. The model parameters have no physical meaning and, thus, no relation to the tensile response of GTX.

The hyperbolic model (Eq. 3) fitted well the experimental data (Table 4; Fig. 4), with $R^{2}$ of 0.997-0.999. Hyperbolicbased models are often associated with tensile parameters of the material, as represented in Eqs. 5 and 6. Herein the initial stiffness was estimated as the tangent stiffness for $0 \%$ strain, obtained from the order 6 polynomial models. Figure 5 illustrates how parameters $a$ and $b$ for the hyperbolic models related to the tensile parameters of GTX. The data (Fig. 5a, c) show that $a$ and $b$ do not follow Eqs. 6 and 7. However, that changes if correction factors are included for $J_{i}$ and for $T_{\max }$, herein designated as $C_{J}$ and $C_{T}$, for $a$ and $b$, respectively (Eqs. 8 and 9).

$a=\frac{C_{J}}{J_{i}}$.

$b=\frac{C_{T}}{T_{\max }}$.

These correction factors were derived for each type of sample studied, to ensure the corresponding parameters $a$ or $b$, obtained from curve fitting, were related to $J_{i}$ or $T_{\max }$ for the same type of sample. For the undamaged sample (GTX UND) $C_{J}=107.64$ and $C_{T}=0.584$. These correction factors changed after damage (Table 5), showing that they 
Fig. 4 Simple constitutive models (polynomial, order 4 and 6, and hyperbolic) representing the tensile response of GTX (representative specimens): a undamaged (UND) and submitted to damage in laboratory: mechanical (MEC); b with synthetic (SYN), c granite (GRA) and d limestone (LIM) aggregates; $\mathbf{e}$ abrasion (ABR); and $\mathbf{f}$ sequential mechanical and abrasion damage (MEC $\mathrm{SYN}+\mathrm{ABR})$

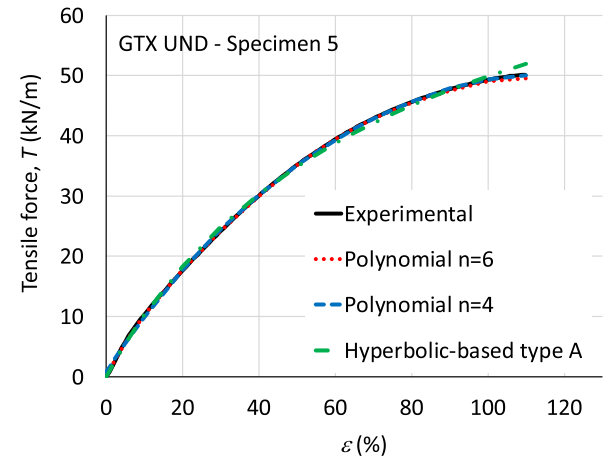

a)

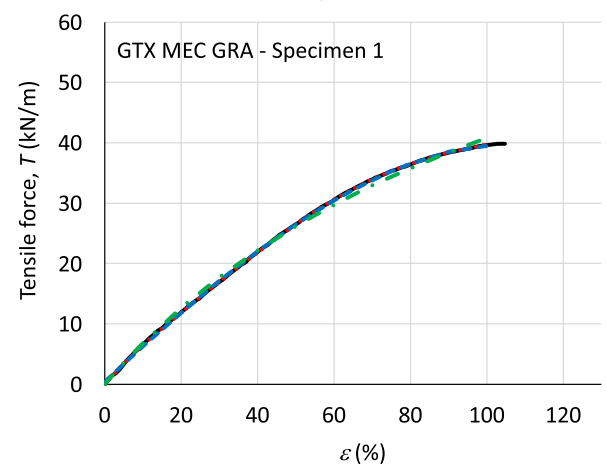

c)

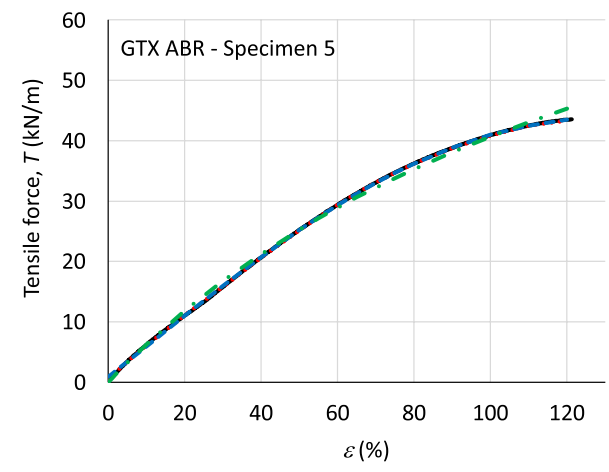

e)

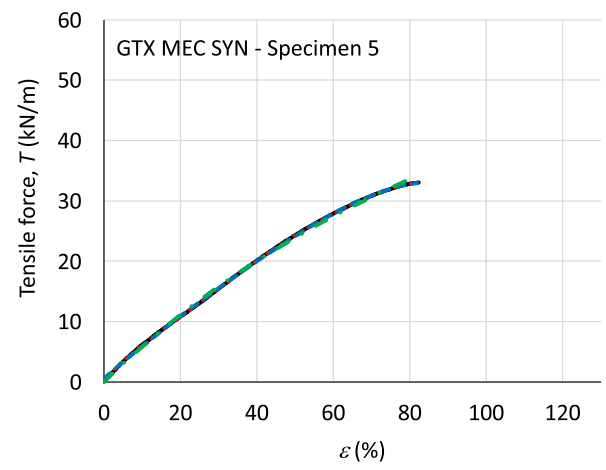

b)

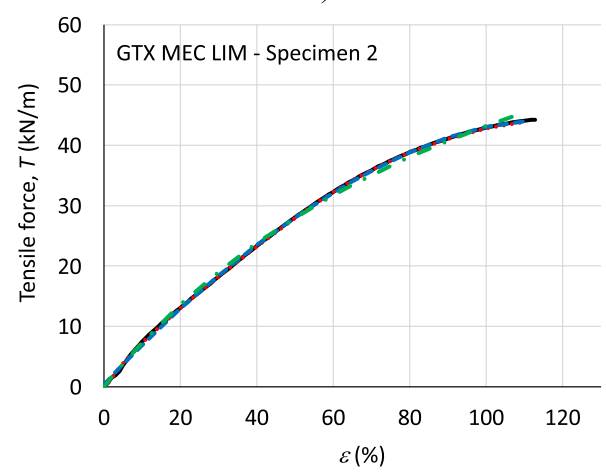

d)

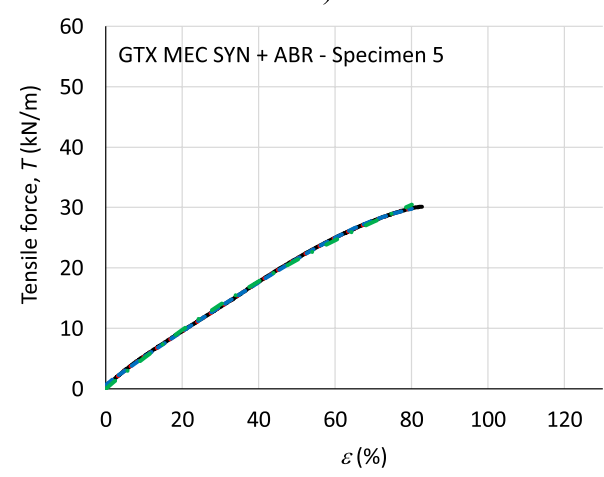

f) are not material constants and that they are influenced by aspects relative to the durability of GTX, including the type of damage induced and the aggregate used for the mechanical damage test.

One of the goals of this work was to estimate model parameters for the damaged samples using tensile properties of the undamaged sample and the corresponding model parameters. Some trends were noticed and analysed further to then proposed relations for estimating model parameters after damage. The reduction factor for the tensile strength of each sample, $\mathrm{RF}_{\text {dam }}$ (Eq. 10), can be used for estimating the correction factor $C_{T}$ obtained for each type of sample studied (Fig. 6a and Eq. 11). Therefore, the parameter $b$ for each type of sample can be estimated reasonably using Eq. 12, which does not depend on the damage induced. This is consistent with the values for parameter $b$ presented in Table 4: after damage $b$ was the practically the same for all damaged samples, although $8 \%$ and $17 \%$ smaller than for the undamaged samples of GTX.

$\mathrm{RF}_{\text {dam }, T}=\frac{T_{\text {max, und }}}{T_{\text {max,dam }}}$.

$C_{T, \text { dam }}=C_{T, \text { und }} / \mathrm{RF}_{\text {dam }, T}$.

$b_{\text {dam }}=\frac{C_{T, \text { dam }}}{T_{\text {max dam }}} \sim \frac{C_{T, \text { und }}}{T_{\text {max,und }}}$.

For the damaged samples, parameter $a$ can be reasonably estimated from Eq. 13 (Fig. 6b), combining the model parameter $a$ for the undamaged sample $\left(a_{\text {und }}\right)$ and 
Fig. 5 Hyperbolic model parameters: a parameter a versus $1 / J_{i}$; b parameter $a$ versus $1 / J_{i}$ with correction factor $C_{J}$; c parameter b versus $1 / T_{\max } ; \mathbf{d}$ parameter $b$ versus $1 / T_{\max }$ with correction factor $C_{T}$

Table 5 Correction factors $C_{J}$ and $C_{T}$ obtained for the hyperbolic models for different types of samples of GTX

Fig. 6 Estimates of the model parameters for the damaged samples: a parameter $C_{T}$ versus $C_{T}$, und $/ \mathrm{RF}_{\mathrm{dam}, T}, \mathbf{b}$ parameter $a$ versus $a_{\text {und }} * \mathrm{RF}_{J i}$
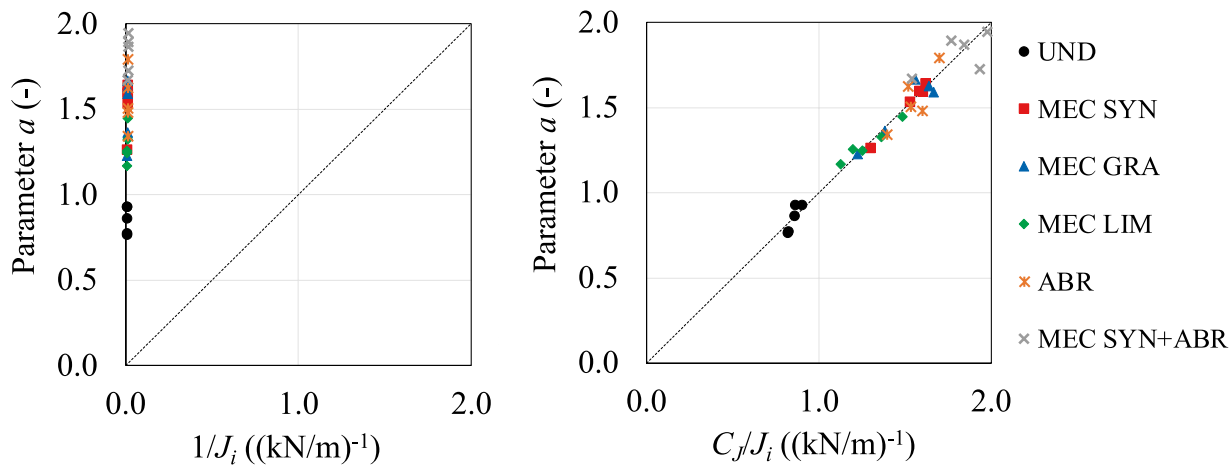

a)

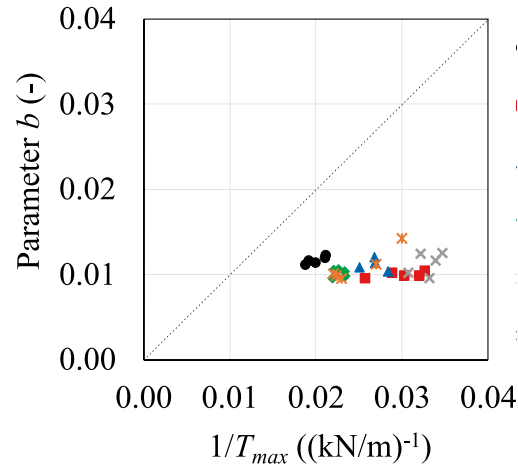

c) b)

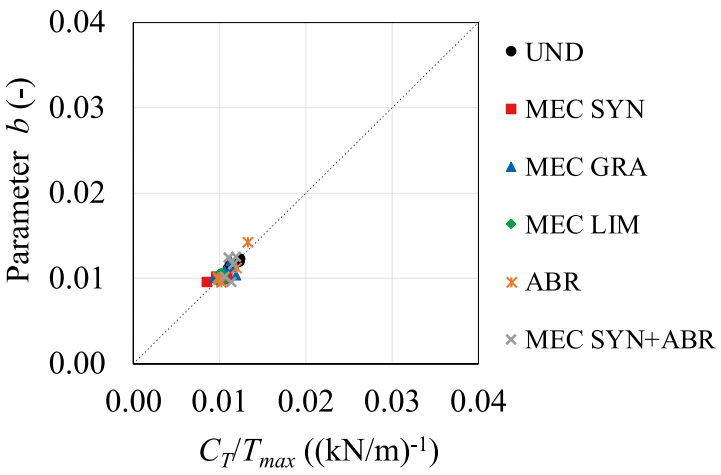

d)

\begin{tabular}{lcccccc}
\hline Correction factor & UND & \multicolumn{2}{l}{ MEC } & & ABR & MEC SYN + ABR \\
\cline { 2 - 5 } & & SYN & GRA & LIM & & \\
\hline$C_{J}$ & 107.64 & 121.61 & 111.62 & 112.51 & 101.98 & 112.07 \\
$R^{2}\left(C_{J}\right)$ & 0.997 & 1.000 & 0.998 & 0.999 & 0.997 & 0.995 \\
$C_{T}$ & 0.584 & 0.332 & 0.4199 & 0.4481 & 0.4426 & 0.3422 \\
$R^{2}\left(C_{T}\right)$ & 0.999 & 0.996 & 0.994 & 0.998 & 0.997 & 0.991 \\
\hline
\end{tabular}

$U N D$ undamaged, $M E C$ damage in laboratory, $S Y N$ synthetic aggregate, GRA granite aggregate, LIM limestone aggregate, $A B R$ abrasion, $M E C S Y N+A B R$ sequential mechanical and abrasion damage

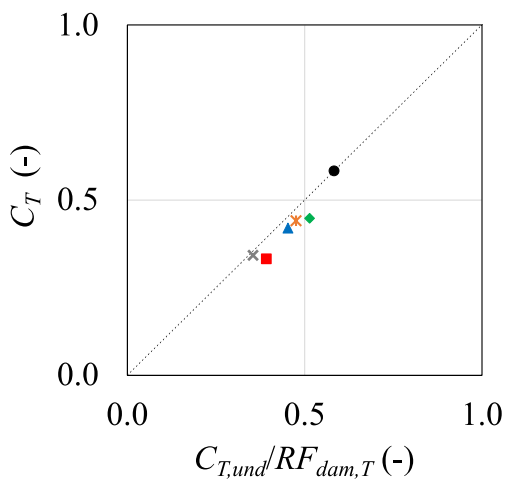

a)

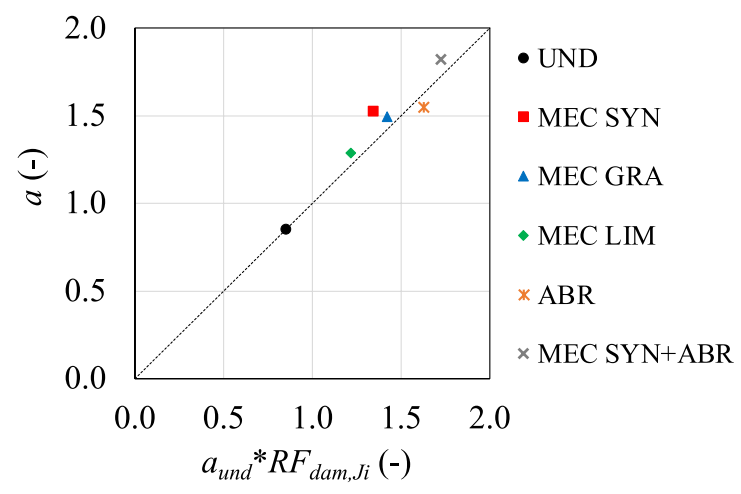

b) 
the reduction factor for the initial stiffness $\left(\mathrm{RF}_{\mathrm{dam}, J i}\right)$. This reduction factor can be calculated using Eq. 10 and replacing the tensile strength, $T_{\max }$, by the corresponding values of $J_{i}$.

$a_{\text {dam }} \sim a_{\text {und }} \times \mathrm{RF}_{\text {dam }, J i}$.

\section{Conclusions}

In this paper, the short-term tensile response of a geotextile was approximated using simple constitutive models (polynomial and hyperbolic). The influence of two endurance durability factors on that response was analysed, namely mechanical and abrasion damage, acting independently and sequentially; the influence of the aggregate used to induce mechanical damage was also analysed. From the results the main conclusions can be summarised:

- The polynomial models (order 4 and order 6) approximated the short-term tensile experimental data very well and better than the hyperbolic model. However, the polynomial model parameters have no physical meaning.

- The hyperbolic-model parameters $(a$ and $b$ ) obtained from the experimental data did not always have the physical meaning referred in the literature. To ensure these model parameters had relevant physical meaning, correction factors for the initial stiffness $\left(C_{J}\right)$ and for the tensile strength $\left(C_{T}\right)$ were introduced. The correction factors were not material characteristics, as they were affected by mechanical and abrasion damage, isolated or sequential, and by the type of aggregate in contact with GTX.

- The hyperbolic-model parameters of the damaged samples were estimated from those of the undamaged samples using properties of the undamaged sample of GTX, namely its tensile strength and the corresponding correction factor $\left(C_{T}\right)$, and the reduction factors allowing for damage applicable to the properties represented by the model parameters $a$ and $b$, respectively the initial stiffness $\left(J_{i}\right)$ and the tensile strength $\left(T_{\max }\right)$.

- The hyperbolic-model parameter $b$ was approximately constant for all samples of GTX and, thus, little affected by the durability factors studied.

The model developed and the equations proposed to estimate constitutive-model parameters after damage will have a significant positive impact on the design of geosynthetics. These proposals enable a simple way of estimating the tensile response of GTX after mechanical and abrasion damage. The base information used are:
- undamaged material - tensile properties (tensile strength and initial stiffness) and correction factors for the tensile strength and initial stiffness;

- damaged samples - the corresponding reduction factors allowing for damage and applicable to two key properties in the design of geosynthetics: tensile strength and stiffness.

These trends need to be confirmed for other materials, but they are good indicators of links between model parameters representing the tensile response of the undamaged material and the material submitted to mechanical and abrasion damage, isolated or sequentially.

Thus, it will be possible to considerer the effects of the durability of geosynthetics in their design by implementing these constitutive models, particularly when using the finite element method or the finite differences method. Therefore, more realistic designs and analysis will be possible.

Acknowledgements This work was supported by the Foundation for Science and Technology (FCT)—Aveiro Research Centre for Risks and Sustainability in Construction (RISCO), Universidade de Aveiro, Portugal [FCT/UIDB/ECI/04450/2020]. This work was financially supported by: Base Funding-UIDB/04708/2020 of the CONSTRUCTInstituto de I\&D em Estruturas e Construções-funded by national funds through the FCT/MCTES (PIDDAC).

Author contributions The individual contributions of each author are highlighted as follows: AMP, data analysis, methodology, investigation, validation, writing (reviewing and editing); MP-L, conceptualisation, methodology, investigation, data analysis, validation, and writing (original draft).

Funding Not applicable.

\section{Declarations}

Conflict of interest The authors declare no conflict of interest.

Data availability The data presented in this study are available on request from the corresponding author.

Code availability Not applicable.

\section{References}

1. Koerner RM (2005) Designing with geosynthetics, 5th edn. Prentice Hall, Upper Saddle River

2. Perkins SW (2007) Part I-general issues, chapter 2-the material properties of geosynthetics, geosynthetics in civil engineering. Sarsby RW (eds). Woodhead Publishing, Cambridge

3. Austin RA (1998) Installation effects on geosynthetics Seminar volume on installation damage in geosynthetics. ERA Technology, Leatherhead, pp 3.2.1-3.2.10

4. Watn A, Chew SH (2002) Geosynthetic damage-from laboratory to field. Proceedings of the 7th international conference on geosynthetics, Nice, France vol, 4, pp. 1203-1226 
5. Hufenus R, Ruegger R, Flum D, Sterba IJ (2005) Strength reduction factors due to installation damage of reinforcing geosynthetics. Geotext Geomembr 23(5):401-424

6. Pinho-Lopes M, Lopes ML (2014) Tensile properties of geosynthetics after installation damage. Environ Geotech 1(3):161-178

7. Bräu G (1998) Experience with damage during installations in Germany-field and laboratory testing. ERA Technology, Leatherhead, pp 211-2115

8. Allen TM, Bathurst RJ (1994) Characterization of geosynthetic load-strain behavior after installation damage. Geosynth Int 1(2):181-199

9. Bathurst RJ, Huang B, Allen TM (2011) Analysis of installation damage tests for LRFD calibration of reinforced soil structures. Geotext Geomembr 29(3):323-334

10. BS 8006-1 (2010) +A1 (2016) Code of practice for strengthened/ reinforced soils and other fills. British Standards Institute, London

11. ASTM D5818-11 (2018) Standard practice for exposure and retrieval of samples to evaluate installation damage of geosynthetics. ASTM International, West Conshohocken

12. SINTEF (2012) NorGeoSpec 2012-Nordic system for the certification and specification of geosynthetics and geosynthetic-related products. Stiftelsen for Industriell og Teknisk Forskning, Trondheim, Norway. https://www.norgeospec.org/data/uploads/dateien/ sintef_guideline_27-09.pdf.

13. Huang C-C (2006) Laboratory simulation of installation damage of a Geogrid. Geosynthetics Int. https://doi.org/10.1680/gein. 2006.13.3.120

14. Huang C-C, Chiou S-L (2006) Investigation of installation damage of some geogrids using laboratory tests. Geosynth Int 13(1):23-35

15. Huang C-C, Wang Z-H (2007) Installation damage of geogrids: influence of load intensity. Geosynth Int 14(2):65-75

16. BSI ENV ISO 10722-1 (1998) Geotextiles and geotextile-related products-procedure for simulating damage during installationpart 1: Installation in granular materials. BSI, London

17. BSI EN ISO 10722:2007 (2007) Geosynthetics. Index test procedure for the evaluation of mechanical damage under repeated loading. Damage caused by granular material. BSI, London

18. Paula AM, Pinho-Lopes M, Lopes ML (2004) Damage during installation laboratory test. Influence of the type of granular material. Proc. of the EUROGEO 3, 3rd European conf. on geosynthetics, vol. 2, pp.603-606, Münich, Germany

19. Carlos D, Carneiro JR, Pinho-Lopes M, Lopes ML (2015) Effect of soil grain size distribution on the mechanical damage of nonwoven geotextiles under repeated loading. Int J Geosynth Ground Eng 1(1):1-7

20. Rosete A, Mendonça Lopes P, Pinho-Lopes M, Lopes ML (2013) Tensile and hydraulic properties of geosynthetics after mechanical damage and abrasion laboratory tests. Geosynth Int 20(5):358374. https://doi.org/10.1680/gien.13.00022

21. Pinho-Lope M, Lopes ML (2015) Synergisms between laboratory mechanical and abrasion damage on mechanical and hydraulic properties of geosynthetics. Trans Geotech 4:50-63

22. Cheah C, Gallage C, Dawes L, Kendall P (2016) Impact resistance and evaluation of retained strength on geotextiles. Geotext Geomembr 44:549-556

23. Pinho-Lopes M, Paula AM, Lopes ML (2018) Long-term response and design of two geosynthetics: effect of field installation damage. Geosynth Int 25(1):98-117

24. Allen TM, Bathurst RJ (1996) Combined allowable strength reduction factor for geosynthetic creep and installation damage. Geosynth Int 3(3):407-439

25. Pinho-Lopes, M., Lopes, M. L., Recker, C. \& Muller-Rocholz, J. (2001) Analysis of the combined effect of installation damage and creep of geosynthetics. International conference composites in construction (CCC2001), Porto, Portugal, A A Balkema Publishers, Leiden, pp. 379-384
26. Pinho-Lopes M, Recker C, Lopes ML, Mueller-Rochholz J (2002) Experimental analysis of the combined effect of installation damage and creep of geosynthetics-new results. Proceedings of the 7th international conference on geosynthetics, Nice, France, vol. 4, pp. 1539-1544

27. Greenwood JH (2002) The effect of installation damage on the long-term design strength of a reinforcing geosynthetic. Geosynth Int 9(3):247-258

28. Paula AM, Pinho-Lopes M, Lopes ML (2008) Combined effect of damage during installation and long-term mechanical behaviour of geosynthetics. Paper 185, Theme 3 (durability and long term performance) of the 4th European geosynthetics conference, Abstract Book, pp. 39-46, CD-ROM, Edinburgh, UK

29. Cho SD, Lee KW, Cazzuffi DA, Jeon HY (2006) Evaluation of combination effects of installation damage and creep behavior on long-term design strength of geogrids. Polym Testing 25(6):819-828

30. Jeon H-Y, Bouazza A (2010) Experimental investigation of installation damage for geogrids. Proc Inst Civ Eng Ground Improv 163(4):197-205

31. Bathurst RJ, Miyata Y (2015) Reliability-based analysis of combined installation damage and creep for the tensile rupture limit state of geogrid reinforcement in Japan. Soils Found 55(2):437-446

32. Pinho-Lopes M, Paula AM, Lopes ML (2015) Pull-out response of geogrids after installation. Geosynth Int 22(5):339-354

33. Pinho-Lopes M, Paula AM, Lopes ML (2016) Soil-geosynthetic interaction in pullout and inclined-plane shear for two geosynthetics exhumed after installation damage. Geosynth Int 23(5):331-347

34. Margarida Pinho-Lopesa and Maria de LurdesLopes (2020) Influence of mechanical damage induced in laboratory on the soil-geosynthetic interaction in inclined-plane shear. Constr Build Mater 185:468-480

35. Hausmann MR, Ring GJ, Pitsis SE (1990) Abrasion of geotextiles in railway track applications. In: Proceedings of the 4th international conference on geotextiles, geomembranes and related products, pp. 193-196

36. Huang C-C, Liao C-C (2007) Abrasion damage of geogrids induced by turbid flow. Geotext Geomembr 25:128-138

37. BSI EN ISO 13427:2014 (2014) Geosynthetics. Abrasion damage simulation (sliding block test). BSI, London, UK

38. Huang CC, Tzeng YS, Liao CJ (2007) Laboratory tests for simulating abrasion damage of a woven geotextile. Geotext Geomembr 25:293-301

39. BSI PD ISO/TR 20432 (2007) Guidelines to the determination of long-term strength of geosynthetics for soil reinforcement. BSI, London, UK

40. Greenwood JH, Schroeder HF, Voskamp W (2012) Durability of geosynthetics. CUR Building \& Infrastructure, The Netherlands, p 243

41. Paula, AM, Pinho-Lopes, M (2018a) Simple constitutive models to represent the effect of mechanical damage and abrasion on the short-term load-strain response of geosynthetics. 9th European conference on numerical methods in geotechnical engineering. Porto, Portugal, p.8

42. Paula, AM and Pinho-Lopes, M (2018b) Simple constitutive models to study the influence of installation damage on the load-strain response of two geogrids. 11th international conference on geosynthetics, Seul, Korea, p. 8

43. BS EN ISO 10319 (2008) Geosynthetics. Wide-width tensile test. BSI, London

44. BS EN ISO 10722 (2019) Geosynthetics. Index test procedure for the evaluation of mechanical damage under repeated loading. Damage caused by granular material (laboratory test method). BSI, London 
45. EN ISO 13427 (1998) Geotextiles and geotextile-related products. Abrasion damage simulation (sliding block test). BSI, London

46. Bathurst RJ, Kaliakin VN (2005) Review of numerical models for geosynthetics in reinforcement applications. Computer methods and advances in geomechanics: 11th intern. conf. of the international association for computer methods and advances in geomechanics, Torino, pp. 19-24, 4: 407-416.

47. Liu H, Ling HI (2007) Unified elastoplastic-viscoplastic bounding surface model of geosynthetics and its applications to geosynthetic reinforced soil-retaining wall analysis. J Eng Mech 133(7):801-815

Publisher's Note Springer Nature remains neutral with regard to jurisdictional claims in published maps and institutional affiliations. 